\title{
Effect of Infectious Bursal Disease (Ibd) Vaccines on Infection of Salmonella Heidelberg in Broiler Chickens
}

\section{-Author(s)}

Marin-Gómez SY' (D) https://orcid.org/0000-0002-9374-5591 Martins NRS' (iD https://orcid.org/0000-0003-1797-3522 Fernando FS" (iD https://orcid.org/0000-0003-0040-821X Coelho HLG' (D) https://orcid.org/0000-0003-1460-0202 Freitas Neto OC' (iD https://orcid.org/0000-0002-1437-069X

Department of Preventive Veterinary Medicine, Federal University of Minas Gerais (UFMG), Belo Horizonte, Minas Gerais, Brazil.

" Boehringer Ingelheim Animal Health, São Paulo, Brazil.

\section{-Mail Address}

Corresponding author e-mail address Oliveiro Caetano de Freitas Neto

Universidade Federal de Minas Gerais, UFMG, Escola de Veterinária, Departaᄀmento de Medicina Veterinária Preventiva, Av. Antônio Carlos, 6627, Caixa Postal 567. Campus Pampulha, CEP: 30123-970, Belo Horizonte, Minas Gerais, Brasil.

Phone: (55 31) 3409-2091

Email: oliveirocaetano@yahoo.com.br

\section{- Keywords}

Salmonella, faecal colonization, HVT-VP2 vector, immune-complex, depletion.

\section{ABSTRACT}

Salmonella Heidelberg (SH) has represented a great concern to the Brazilian poultry industry in the last years. It is known that immunosuppression in poultry is a contributing factor to increase Salmonella faecal shedding and to disturb control programmes. Not only infectious bursal disease (IBD) virus but also some live vaccines have been reported to induce immunosuppression. In the present study we assessed the effects of two live vaccines against IBD on SH-infected broiler chicks. At 7 days of age, birds of three groups (vaccinated with recombinant HVT-IBD vector, with immune complex-IBD vaccine and unvaccinated) were orally challenged with $1 \times 10^{8} \mathrm{CFU}$ of $\mathrm{SH}$. A group of hatchmates remained unvaccinated/unchallenged to serve as negative controls. Caecal colonization and systemic invasion were evaluated by bacterial enumeration at 1, 3, 5, 7 and 14 days post-infection (Dpi) and $\mathrm{SH}$ faecal shedding assessed by cloacal swabs at 3, 7, 10 and 14 Dpi. The counts of $\mathrm{SH}$ in caecal contents were higher in birds vaccinated with immune complex-IBD than in those that received the HVT-IBD vector vaccine at 5,7 and $14 \mathrm{dpi}(p<0.01)$. There were no statistical differences in bacterial counts in liver and spleen among birds of different groups. Cloacal swabs also indicated that the birds vaccinated with immune complex-IBD shed more SH than those vaccinated with HVT-IBD vector or those unvaccinated $(p<0.01)$. The results of the present study suggested that the immunosuppressive effect of the immune complex-IBD vaccine helped to increase the SH-faecal shedding in the infected birds.

\section{INTRODUCTION}

Annually, millions of cases of human foodborne diseases worldwide are caused by Salmonella (WHO, 2018). Salmonella serotype Heidelberg $(\mathrm{SH})$ is amongst the most prevalent serotypes isolated from human and non-human sources (CDC, 2018). The majority of the foodborne infections caused by $\mathrm{SH}$ has been associated with poultry meat (Etter et al., 2019). In Brazil, SH represented about $56 \%$ of all Salmonella isolates recovered from broiler carcass in 2017 (Brasil, 2018).

In order to reduce the levels of contamination of poultry products, actions need to be taken at the whole poultry production chain (Gast, 2013). In this context, factors that favor horizontal or vertical transmission of Salmonella at farm level are detrimental to any control programme ( Koutsoumanis et al., 2019).

The immune responses of poultry to Salmonella are crucial to intestinal and systemic clearance (Wigley, 2014). The intestinal immunity, including secretory immunoglobulin A (IgA) is important against Salmonella that colonizes the intestine. While cell mediated immunity plays a role in controlling mainly systemic infection (Withanage et al., 2005). Effects of immunosuppression caused by bursectomy, infection bursal disease (IBD) virus or some IBD vaccines on immune responses to 
Marín-Gómez SY, Martins NRS, Fernando FS, Coelho HLG, Freitas Neto OC
Salmonella serotypes Typhimurium (ST) and Enteritidis (SE) have been demonstrated (Corrier et al., 1991; Arnold \& Holt, 1995; Phillips et al., 1995; Bautista et al., 2004; Arafat et al., 2017). However, this was not yet investigated during infection by $\mathrm{SH}$. In the present study we assessed the effects of two IBD vaccines on caecal colonization, systemic invasion and faecal excretion of $\mathrm{SH}$ in broiler chicks.

\section{MATERIAL AND METHODS}

The experiment was carried out at the facilities of the Avian Diseases Laboratory of the Department of Preventive Veterinary Medicine of the Federal University of Minas Gerais (UFMG).

\section{Bacteria}

A spontaneous nalidixic acid resistant strain of Salmonella enterica subsp enterica serotype Heidelberg (SH Nal') was used. This strain was provided by Professor Angelo Berchieri Junior from the State University of São Paulo, Jaboticabal campus. It was previously isolated from a broiler flock from the Brazilian South region.

\section{Broiler chicks}

One hundred and twenty-one day-old broiler chicks were purchased from a commercial hatchery. The birds were not vaccinated against Marek's disease at the hatchery. On arrival, samples of faeces in the transport cardboard boxes were collected and processed to assure the birds were free of Salmonella spp. (Zancan et al. 2000).

\section{Experimental design}

The chicks were divided in four groups (A, B, C and $D)$ and housed in acclimatised rooms. On day one, the chicks from group A were vaccinated $(0.2 \mathrm{~mL} /$ chick subcutaneously) with a recombinant turkey herpesvirus (HVT) expressing the VP2 gene of IBD virus (HVT-IBD). Meanwhile, the birds of group $B$ were vaccinated $(0.2$ $\mathrm{mL}$ /chick) with a live vaccine with virus coated with anti-IBD antibodies (immune complex-IBD). The birds of group $C$ and $D$ did not receive any IBD and HVT vaccine. On day 7 , the chicks of groups $A, B$ and $C$ were orally challenged with $1 \times 10^{8} \mathrm{CFU}$ of $\mathrm{SH} \mathrm{Nal}$. The birds in group $\mathrm{D}$ were kept as negative control. This experiment was approved by the institutional ethical committee (Protocol 345/2018; approved on 25 February 2019).

\section{Bacteriology}

At 1, 3, 5, 7 and 14 days post-infection (Dpi), five birds from each infected group were euthanized and samples of the spleen, liver and caecal content were collected for bacterial enumeration. Bacterial shedding in faeces was also monitored by cloacal swabs twice a week. All bacteriological procedures followed the methodology described by Berchieri et al. (2001). Briefly, the enumeration of SH Nalr in the samples was estimated by plating aliquots of decimal dilutions onto brilliant green agar (BGA) (Oxoid, US) plates, containing $100 \mu \mathrm{g} / \mathrm{mL}$ of nalidixic acid (Sigma-Aldrich, US). The first dilution of each sample was added to an equal volume of double-strength selenite broth (Oxoid, US) and incubated. The plates and selenite enrichment cultures were also incubated for 24 hours at $37^{\circ} \mathrm{C}$. Cloacal swabs were plated on BGA and further incubated in selenite broth. Those samples for which no bacteria grew on BGA were re-streaked onto new BGA plates from the enriched cultures.

\section{Statistical analysis}

Statistical differences amongst mean counts of $\mathrm{SH} \mathrm{Nal}$ recovered from caecal contents, livers and spleens were determined using Tukey's test. Data on faecal shedding obtained by cloacal swabs were compared by Chi-Square's test. Statistical analyses were performed using GraphPad Prism version 8.0.1 (GraphPad Software, US).

\section{RESULTS}

Examination of the liver, spleen and caecal content of the birds of uninfected control group (D) indicated that they kept $\mathrm{SH}$-free over the experiment.

The results of $\mathrm{SH}$ enumeration in livers, spleens and caecal contents of the birds belonging to groups A (HVT-IBD vector), B (immune complex-IBD) and C (unvaccinated) are shown in table 1 . There were no significant differences among the counts in livers and spleens at 1, 3, 5, 7 and 14 Dpi ( $p>0.05)$. At 1 and 3 Dpi, SH counts in caecal contents were also similar ( $p>0.05$ ). However, at 5 Dpi, birds of group B showed higher counts in caecal contents than those of group A. At 7 Dpi SH counts in caeca of birds of group B were higher than in birds of groups $A$ and $C$ (also in figure 1). At $14 \mathrm{Dpi}$ the amounts of $\mathrm{SH}$ in caeca of birds of group $B$ were still higher than in birds of group A $(p<0.05)$.

$\mathrm{SH}$ shedding was also monitored by cloacal swabs of the birds and the results are displayed in table 2 . The total number of positive cloacal swabs in the birds of group B was also higher than in the birds of group $C(p<0.01)$. If only the direct plating of the swabs is considered, the 
Table 1 - Mean counts of Salmonella Heidelberg (SH Nalr) of five birds in spleen, liver and caecal contents at 1, 3, 5, 7 and 14 days post-infection (Dpi). Values are expressed as means \pm standard deviation of bacterial counts (log 10 CFU/g).

\begin{tabular}{llccc}
\hline \multirow{2}{*}{ Tissue } & Dpi & \multicolumn{3}{c}{ Groups } \\
\cline { 3 - 5 } Spleen & 1 & $\mathrm{~A}(\mathrm{HVT}-\mathrm{IBD}$ vector) & $\mathrm{B}$ (immune complex-IBD) & $\mathrm{C}($ Unvaccinated) \\
& 3 & $0.40 \mathrm{~A} \pm 0.89$ & $1.82 \mathrm{~A} \pm 2.58$ & $1.74 \mathrm{~A} \pm 2.90$ \\
& 5 & $1.06 \mathrm{~A} \pm 1.52$ & $2.36 \mathrm{~A} \pm 2.45$ & $0.40 \mathrm{~A} \pm 0.89$ \\
& 7 & $0.50 \mathrm{~A} \pm 1.00$ & $1.32 \mathrm{~A} \pm 2.04$ & $0.80 \mathrm{~A} \pm 1.10$ \\
& 14 & $0.0 \mathrm{~A} \pm 0.0$ & $0.0 \mathrm{~A} \pm 0.0$ & $0.80 \mathrm{~A} \pm 1.10$ \\
Liver & 1 & $0.40 \mathrm{~A} \pm 0.89$ & $0.40 \mathrm{~A} \pm 0.89$ & $0.80 \mathrm{~A} \pm 1.10$ \\
& 3 & $0.0 \mathrm{~A} \pm 0.0$ & $1.16 \mathrm{~A} \pm 1.70$ & $0.80 \mathrm{~A} \pm 1.10$ \\
& 5 & $0.66 \mathrm{~A} \pm 1.48$ & $1.36 \mathrm{~A} \pm 2.10$ & $0.0 \mathrm{~A} \pm 0.0$ \\
Cecal & 7 & $0.0 \mathrm{~A} \pm 0.0$ & $0.80 \mathrm{~A} \pm 1.10$ & $0.0 \mathrm{~A} \pm 0.0$ \\
content & 14 & $0.0 \mathrm{~A} \pm 0.0$ & $0.40 \mathrm{~A} \pm 0.89$ & $0.0 \mathrm{~A} \pm 0.0$ \\
& 1 & $0.0 \mathrm{~A} \pm 0.0$ & $0.0 \mathrm{~A} \pm 0.0$ & $0.0 \mathrm{~A} \pm 0.0$ \\
& 3 & $6.68 \mathrm{~A} \pm 0.63$ & $6.04 \mathrm{~A} \pm 0.62$ & $6.19 \mathrm{~A} \pm 0.56$ \\
& 5 & $5.48 \mathrm{~A} \pm 2.31$ & $6.61 \mathrm{~A} \pm 0.64$ & $5.81 \mathrm{~A} \pm 0.84$ \\
& 7 & $3.77 \mathrm{~A} \pm 3.46$ & $6.71 \mathrm{~B} \pm 0.38$ & $4.25 \mathrm{AB} \pm 1.34$ \\
\hline
\end{tabular}

Group A: Birds vaccinated with HVT-IBD vector vaccine in the first day of life and challenged with SH at 7 days. Group B: Birds vaccinated with immune complex-IBD in the first day of life and challenged with SH at 7 days. Group C: Birds were not vaccinated with any IBD vaccine and challenged with SH at 7 days. Dpi: Days post-infection. Means followed by different letters in the same row indicate significant differences by Tukey's test (at $p<0.05^{*}$; or $p<0.01^{* *}$ ).

Table 2 - Recovery of Salmonella Heidelberg (SH Nal') of 80 birds of each group by cloacal swabs taken at 3, 7, 10 and 14 days post-infection (Dpi).

\begin{tabular}{|c|c|c|c|c|c|c|c|c|c|}
\hline \multirow{3}{*}{ Dpi } & \multicolumn{9}{|c|}{ Groups } \\
\hline & \multicolumn{3}{|c|}{ A (HVT-IBD vector) } & \multicolumn{6}{|c|}{ B (immune complex-IBD) C (Unvaccinated) } \\
\hline & $\mathrm{D}$ & $E$ & $T$ & $\mathrm{D}$ & $\mathrm{E}$ & $T$ & $\mathrm{D}$ & $E$ & $\mathrm{~T}$ \\
\hline 3 & 18 & 10 & 28 & 29 & 1 & 30 & 21 & 6 & 27 \\
\hline 7 & 6 & 10 & 16 & 11 & 8 & 19 & 6 & 7 & 13 \\
\hline 10 & 3 & 12 & 15 & 5 & 14 & 19 & 1 & 14 & 15 \\
\hline 14 & 1 & 12 & 13 & 5 & 7 & 12 & 0 & 8 & 8 \\
\hline Total & $25 \mathrm{~A}$ & 39 & 64 & $44 B^{* *}$ & 27 & 71 & $25 \mathrm{~A}$ & 31 & 56 \\
\hline
\end{tabular}

Group A: Birds vaccinated with HVT-IBD vector vaccine in the first day of life and challenged with SH at 7 days. Group B: Birds vaccinated with immune complex-IBD in the first day of life and challenged with SH at 7 days. Group C: Birds were not vaccinated with any IBD vaccine and challenged with SH at 7 days. Dpi: Days post-infection; D: positive result after direct plating of swab; E: positive result after enrichment; T: Total $=D+E$. Means followed by different letters in the row indicate significant differences by Chi-Square's test ( $p<0.01)$.

number of positives (44) in group B would be higher than in groups $A(25)$ and $C(25)(p<0.01)$.

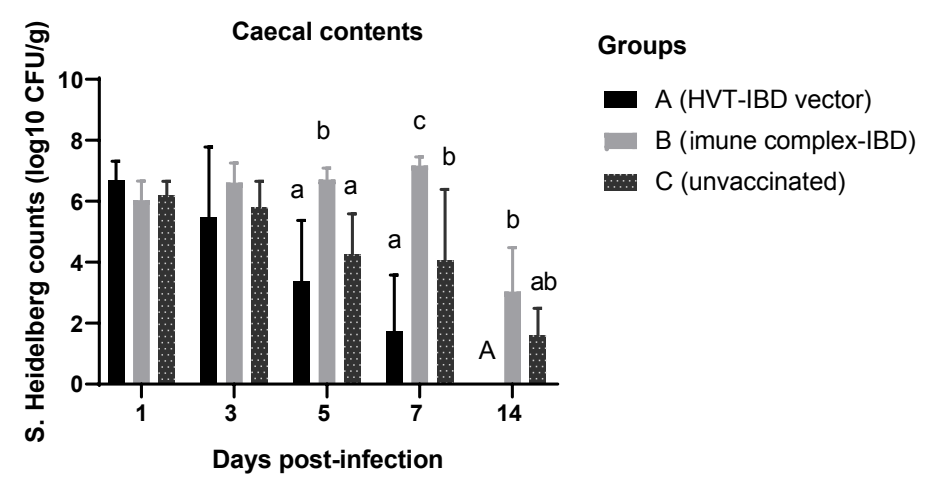

Figure 1-Salmonella Heidelberg (SH) counts in caecal contents at 1, 3, 5, 7 and 14 days post-infection (Dpi). Group A: Birds vaccinated with HVT-IBD vector vaccine in the first day of life. Group B: Birds vaccinated with immune complex-IBD in the first day of life. Group C: Birds were not vaccinated with any IBD vaccine. All birds were challenged with $\mathrm{SH}$ at 7 days. Different letters on the plots mean there was statistical significance by Tukey's test among groups by Dpi.

\section{DISCUSSION}

There are several tools (probiotics, vaccines, organic acids, etc.) available to control Salmonella in poultry farming (Vandeplas et al., 2010; Schneitz et al., 2016). However, they will have good effects only if applied together with biosecurity measures and the environmental challenge is not too high (Barrow, 2000; Gast, 2013). Therefore, immunosuppressive agents that favour Salmonella shedding and consequently the environmental contamination may affect the effectiveness of control programmes.

Studies have indicated that not only infectious bursal disease virus, but also some live IBD vaccines can reduce B lymphocytes populations (Avakian et al., 2001) and consequently affect the immune responses to other pathogens, including Salmonella (Arafat et al, 2017). Camilotti et al., (2016) described severe atrophy 
Marín-Gómez SY, Martins NRS,

Fernando FS, Coelho HLG,

Freitas Neto OC of the Bursa of Fabricius (BF) in birds vaccinated with an immune complex-IBD vaccine, whereas birds that received HVT-IBD vector vaccine showed preserved $B F$ tissue.

It is proposed that cell-mediated immunity is important for tissue clearance of invasive Salmonella in poultry, while IgA responses seem to be key to the intestinal clearance (Withanage et al., 2005). A study of Desmidt et al. (1998) with Salmonella Enteritidis (SE)infected bursectomized chickens showed increased faecal excretion and higher caecal counts, while having normal SE-counts in internal organs, indicating a protective effect of IgA against intestinal colonization. Similar results were observed in the present study, in which birds vaccinated with an immune complex-IBD vaccine had more Salmonella Heildelbeg (SH) in the intestine than those vaccinated with HVT-IBD vector and no differences were observed in spleen and liver over the experiment. Apparently, only humoral responses were compromised in the birds vaccinated with immune complex-IBD. Arafat et al. (2017) also reported that broiler chicks vaccinated with a live $\mathrm{IBD}$ vaccine excreted more SE than the unvaccinated birds and correlated this finding with lower levels of intestinal $\lg A$.

In the present study, birds vaccinated with an immune-complex IBD vaccine showed lower ability to clear intestinal $\mathrm{SH}$.

\section{ACKNOWLEDGEMENTS}

We are grateful to Mr. Mailson da Silva Teixeira and to Ms. Anna Gabriella Guimarães of the Department of Preventive Veterinary Medicine of the Federal University of Minas Gerais, for technical support.

\section{REFERENCES}

Arafat N, Eladl AH, Mahgoub H, El-Shafei RA. Effect of infectious bursal disease (IBD) vaccine on Salmonella Enteritidis infected chickens. Vaccine 2017;35(29):3682-3689.

Arnold JW, Holt PS. Response to Salmonella enteritidis infection by the immunocompromised avian host. Poultry Science 1995;74(4):656-65.

Avakian AP, Whitfill CE, Haddad EE, Van Den Wijngaard JK, Chettle NJ. The characteristics of infectious bursal disease virus-antibody complex vacines and their application on broilers with maternal immunity. Proceedings of the 3rd Meeting of Working Group, COST Action 839. Passive protection and vaccination (current and future possibilities) in the presence of maternally derived antibody; 2001; Pulawy. Poland.

Barrow PA. The paratyphoid salmonellae. Revue Scientifique et Technique 2000;19(2):339-352

Bautista DA, Elankumaran S, Hecker RA. Effect of a variant infectious bursal Disease virus (E/Del) on Salmonella typhimurium infection in commercial broiler chickens. Avian Diseases 2004;48(2):361-369.
Berchieri JRA, Murphy CE, Marston K, Barrow PA. Observation on the persistence and vertical transmission of Salmonella enterica serovars Pullorum and Gallinarum in chickens: effect of bacterial and host genetic background. Avian Pathology 2001;30(3):221-231

Brasil. Ministério da Agricultura, Pecuária e Abastecimento. Entenda melhor - Salmonela em carne de frango [nota técnica]. Brasília DF; 2018. Available from: http://www.agricultura.gov.br/assuntos/ inspecao/produtos-animal/arquivos-publicacoes-dipoa/entendamelhor-salmonela-em-carne-de-frango/@@download/file/Nota\%20 t\%C3\%A9cnica\%20Salmonella\%20CRISC\%2012.03.2018.pdf

Camilotti E, Moraes LB, Furian TQ, Borges KA, Moraes HLS, Salle CTP. Infectious bursal disease: pathogenicity and immunogenicity of vaccines. Brazilian Journal of Poultry Science 2016;18(2):303-308

CDC - Center for Disease Control and Prevention. National enteric disease surveillance: salmonella annual report 2016. Washington; 2016. Available from: https://www.cdc.gov/nationalsurveillance/pdfs/2016Salmonella-report-508.pdf

Corrier DE, Hargis B, Hinton AJr, Lindsey D, Caldwell D, Manning J, et al. Effect of anaerobic cecal microflora and dietary lactose on colonization resistance of layer chicks to invasive Salmonella enteritidis. Avian Disease 1991;35(2):337-43

Desmidt M, Ducatelle R, Mast J, Goddeeris BM, Kaspers B, Haesebrouck F. Role of the humoral immune system in Salmonella enteritidis phage type four infection in chickens. Veterinary Immunology and Immunopathology 1998;63(4):355-367.

Etter AJ, West AM, Burnett JL, Wu ST, Veenhuizen DR, Ogas RA, et al Salmonella enterica subsp. enterica serovar Heidelberg food isolates associated with a salmonellosis outbreak have enhanced stress tolerance capabilities. Applied and Environmental Microbiology 2019:85(16):e01065-19.

Gast R. Paratyphoid infections. In: Swayne DE, Glisson JR, McDougald LR Nolan LK, Suarez DL, Nair VL, editors. Diseases of poultry. 13th ed. Ames: Wiley-Blackwell; 2013. p.693-706.

Koutsoumanis K, Allende A, Alvarez-Ordonez A, Bolton D, Bover-Cid S, Chemaly M. Salmonella control in poultry flocks and its public health impact. European Food Safety Authority Journal 2019;17(2): 5596.

Majowicz SE, Musto J, Scallan E, Angulo FJ, Kirk M, O'Brien SJ, et al International Collaboration on Enteric Disease 'Burden of Illness' Studies. The global burden of nontyphoidal Salmonella gastroenteritis. Clinical Infectious Diseases 2010;50(6):882-889.

Phillips RA, Opitz HM. Pathogenicity and persistence of Salmonella enteritidis and egg contamination in normal and infectious bursa disease virus-infected leghorn. Avian Diseases 1995;39(4):778-787.

Schneitz C, Koivunen E, Tuunainen P, Valaja J. The effects of a competitive exclusion product and two probiotics on Salmonella colonization and nutrient digestibility in broiler chickens. The Journal of Applied Poultry Research 2016;25(3):396-406.

Vandeplas S, Dauphin RD, Beckers Y, Thonart P, Théwis A. Salmonella in chicken: current and developing strategies to reduce contamination at farm level. Journal of Food Protection 2010;73(4):774-785.

WHO - World Health Organization. Salmonella (non-typhoidal). Genebra; 2018. Available from: https://www.who.int/en/news-room/fact-sheets/ detail/salmonella-(non-typhoidal).

Wigley P. Salmonella enterica in the chicken: how it has helped our understanding of immunology in a non-biomedical model species. Frontiers Immunology 2014;10(5):482

Withanage GSK, Wigley $\mathrm{P}$, Kaiser P, Mastroeni P, Brooks $\mathrm{H}$, Powers $\mathrm{C}$, et al. Cytokine and chemokine responses associated with clearance of a primary Salmonella enterica serovar Typhimurium infection in the chicken and in protective immunity to rechallenge. Infection and Immunity 2005;73(8):5173-5182.

Zancan FB, Berchieri Junior A, Fernandes SA, Gama NMSQ. Salmonella spp. investigation in transport box of day old birds. Brazilian Journal of Microbiology 2000;31(3):230-232. 